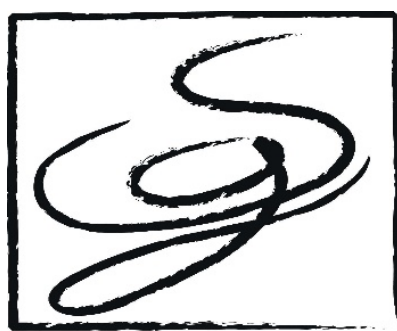

SEMINARIO DE INUESTIGACION DE GÉNERO Y ESTUDIOS BULTURALES

\section{Espacio, poder y representación feminista en prácticas teatrales de la región del Noroeste Argentino}

\author{
Marina Rosenzvaig \\ Universidad Nacional de Tucumán- Universidad de Sevilla \\ ARTES.Marina.Rosenzvaig@webmail.unt.edu.ar
}

\begin{abstract}
Fecha de recepción: 06/07/2021 Fecha de evaluación: 03/08/2021
\end{abstract}
Fecha de aceptación: 09/09/2021

\title{
Resumen
}

En el presente artículo nos proponemos analizar tres dimensiones de prácticas teatrales feministas descoloniales desarrolladas en la región Noroeste Argentino, sucedidas simultáneamente entre los años 2015 al 2020. Gestiones institucionales en teatro, teatralidades de las manifestaciones callejeras y virtuales y obras de teatro feministas se proponen disputar los espacios de poder y de acción, y discutir las representaciones artísticas y políticas mientras se suman a las agendas y demandas de género. Estas prácticas teatrales se cruzan, se retroalimentan y se potencian en el trabajo en simultáneo y comparten también protagonistas. Se encuentran enmarcadas en las masivas movilizaciones en contra de los femicidios del Ni Una Menos y de la lucha por el aborto legal, seguro y gratuito en Argentina.

Palabras Clave: Descolonial, Feminismo, Militancia, Noroeste argentino, Representación, Teatro

\begin{abstract}
In this article we propose to analyze three dimensions of descolonial feminist theatrical practices developed in the Argentine Northwest region, which occurred simultaneously between 2015 and 2020. Institutional management in Theatre, theatricalities of street and virtual demonstrations, and feminist theatre plays propose to dispute the spaces of power and action and discuss artistic and political representations while adding to gender agendas and demands. These theatrical practices intersect, feed off
\end{abstract}


each other and are promoted simultaneously at work and share protagonists. They are part of the massive mobilizations against the femicides Ni Una Menos and the fight for legal, safe, and free abortion in Argentina.

Key words: decolonial, feminism, militancy, Argentine Northwest, representation, theatre

\section{Introducción}

Entre los años 2015 al 2020 convergen en la región del Noroeste Argentino (NOA) prácticas teatrales que consideramos de una singularidad político-artística cardinal. Confluyen militancias teatreras, gestiones institucionales en teatro, teatralidades de las manifestaciones y proposiciones teatrales con perspectiva feminista descolonial. Estas propuestas se encuentran enmarcadas en un contexto de ferviente activismo y artivismo feministas entre las masivas movilizaciones argentinas en contra de los femicidios del Ni Una Menos, desde el 3 de junio de 2015 en adelante, y las intensas luchas por el derecho al aborto legal, seguro y gratuito, desde el año 2018 hasta su legalización el 30 de diciembre de 2020; y en confluencia con luchas políticas y prácticas artísticas transfronterizas similares.

\section{La región como apuesta política de fortalecimiento y resistencia a la hegemonía capitalina}

El NOA es una parcelación geopolítica formada por cinco provincias ${ }^{1}$, constituida después de la declaración de la independencia en el año 1816, junto a otras cuatro regiones que conforman la República Argentina. El uso del término "regional" ha motivado múltiples problemáticas estético-culturales en distintas épocas, como el peligro de someter la cuestión a folclorismos reduccionistas. Desde las independencias latinoamericanas se establecieron asimetrías económicas y políticas impuestas por la colonización de los cosmopolitismos capitalinos y las oligarquías nacionales que se sustentaron en prácticas y políticas de invisibilización de heterogeneidades territoriales, étnicas y culturales; como el NOA indígena-andino, identidad fundamental oculta bajo el mito de la Argentina predominantemente inmigrante.

El recorte territorial en la región apuesta a una enunciación política en una superposición de doble historia colonial, la impuesta por la dominación de los cosmopolitismos capitalinos que mencionábamos, y la dominación europea. El teórico peruano Aníbal Quijano (1992) lo llamó "colonialidad del poder", el patrón estructural asentado en la Modernidad, y originado en la conquista de América y la consecuente hegemonía económica y cultural europea sobre el resto de los territorios. Según

\footnotetext{
${ }^{1}$ La región Noroeste Argentino limita con Bolivia y Chile y consta de cinco provincias: Jujuy, Salta, Tucumán, Catamarca y Santiago del Estero.
} 
propone el autor se construyó la idea diferenciadora de raza, que dio estatus biológico a "blancos europeos" por sobre el resto de las poblaciones, idea justificadora de las consecuentes relaciones de dominación.

Durante los años 2015 al 2019, en el gobierno neoliberal del presidente Mauricio Macri2 ${ }^{2}$ las históricas desigualdades de nuestro país fueron profundizadas en políticas de mercantilización y homogeneización artística y políticas culturales antidemocráticas, antifederales y antipopulares desde el centro de la Ciudad Autónoma de Buenos Aires. De allí que las prácticas teatrales feministas en nuestros territorios apostaran por un proyecto de fortalecimiento regional como resistencia política a la hegemonía capitalina, acompañando y luchando también por la defensa de derechos humanos y de género junto a la enorme "marea verde y violeta" que mencionamos al inicio de este escrito.

La gestión conservadora del gobierno macrista puso sobre la superficie conflictos políticos preexistentes y que configuran la historia cultural de nuestro país, como así también la explicitación de debates culturales subsumidos en la problemática "globalización". Por un lado, la hegemonía del centro de la Ciudad Autónoma de Buenos Aires, la capital versus lo que despectivamente desde una concepción centralista todavía llaman "el interior", las provincias, que impone una visión única y muchas veces extranjerizante sobre las diversidades y particularidades identitarias de los territorios que conforman la vasta República Argentina. Y, por otro lado, la perspectiva mercadotécnica de las industrias culturales impuesta por el capitalismo trasnacional sobre la cultura en general, y sobre el arte y el teatro en particular; que no solo tiene una finalidad comercial para las prácticas y producciones culturales, sino que oculta particularidades 0 complejidades territoriales.

El debate capital/provincias recorre la historia argentina desde sus inicios republicanos, una visión maniqueísta y dicotómica que comprende discusiones culturales, políticas y económicas de larga data en nuestro país. Sintetizado en el binomio propuesto por el "maestro de la patria" Domingo Faustino Sarmiento en su libro Facundo, o Civilización y Barbarie ${ }^{3}$ del año 1845 (2018), y como bien analizó Maristella Svampa en su tesis doctoral El dilema argentino: civilización o barbarie (2006). La civilización refiere a la representación de la capital, urbana, cosmopolita y cuyo horizonte de expectativa es Europa, y sería asumido por los posicionamientos políticos liberal-conservadores; y en su defecto, del lado contrario se encontraría la barbarie referida a las provincias, rurales o indígenas, con sus invisibilizadas diversidades geográficas y culturales, y la opción política democrático-populista. "Un dispositivo simbólico fundacional" que recorre la historia de la República Argentina, desde la Revolución de Mayo, en el año 1810, y en las décadas sucesivas de

\footnotetext{
${ }^{2}$ Mauricio Macri gobernó el país desde el 10 de diciembre del año 2015 al 9 de diciembre del año 2019.

${ }^{3}$ El libro trata sobre Facundo Quiroga, un caudillo de la provincia de La Rioja, y las luchas entre unitarios y federales, resumido en el conflicto de "civilización o barbarie".
} 
guerras civiles entre "unitarios" (centro) y "federales" (provincias) durante la mayor parte del s. XIX.

Otra categoría útil para pensar estos conflictos es la que opone pulcritud y hedor, propuesta por Rodolfo Kusch en su libro América Profunda (1999), en la que revela la beligerancia entre dos concepciones estético-culturales, la emanada de la otredad "monstruosa" latinoamericana, que resiste a un orden, proporción y mesura impuestas por la concepción eurocéntrica y que le son ajenas histórica, geográfica y culturalmente a nuestros territorios. Las imposiciones estéticas y culturales colaboran a sostener la desigualdad e invisibilizar el conflicto principal que continúa siendo la distribución del dinero, un centro que quiere más recursos y tiene más poder en la estructura económica erigida, y el resto del país que pelea por una redistribución equitativa, y por justicia económica y cultural.

Las políticas hegemónicas mencionadas las vimos impuestas al Instituto Nacional del Teatro (INT), en el período gubernamental señalado, en su intento de formatear $u$ homogeneizar al teatro del país. El INT es un organismo estatal de carácter federal con veinticinco años de funcionamiento, central en el financiamiento y fomento del teatro independiente en todas las provincias argentinas. Institución única en su tipo en la Argentina, con organización federal y poseedor de un Consejo de Dirección colegiado con representación de todas las regiones del país, al que se ingresa por concurso y para representar a cada una de las veinticuatro provincias. La Ley Nacional del Teatro 24.800, largamente peleada por el teatro independiente argentino durante décadas, establece la organización de la institución. Distintas medidas tomadas desde la dirección ejecutiva ${ }^{4}$ del organismo en ese período consumaron ajuste económico, persecución política a opositores dentro de la institución e intento de imposición de una visión hegemónica para las políticas teatrales.

Un sector importante dentro de la institución, como así también desde las comunidades teatrales de distintos puntos del país rápidamente entendimos la necesidad de salir en su defensa. El organismo y los financiamientos para la actividad teatral independiente corrían peligro, como ocurrió con tantas otras instituciones nacionales ${ }^{5}$ empobrecidas y que sufrieron fuertes recortes presupuestarios. Así, organizamos y llevamos a cabo distintas acciones en defensa de la institución y de nuestros derechos vulnerados por la gestión neoliberal.

En la región, las acciones político-teatrales desarrolladas desde la provincia de Jujuy fueron centrales en esta etapa, llevaron la delantera regional de resistencia, proposición de acción crítica y creación alternativa, tanto en las propuestas independientes de obras de teatro como en

\footnotetext{
${ }^{4}$ La Dirección Ejecutiva del INT es uno de los pocos cargos políticos de la institución, nombrado por el Ministerio de Cultura Nación. El director ejecutivo del INT durante el gobierno de Mauricio Macri fue Marcelo Allasino.

5 Durante el gobierno nacional de Mauricio Macri, se achicaron y desfinanciaron ministerios, se despidieron trabajadores, se recortaron presupuestos, y se cerraron cientos de programas de desarrollo territorial en distintas áreas, puestos en marcha en los gobiernos anteriores de Néstor y Cristina Kirchner.
} 
proyectos socio-artísticos desde distintos colectivos, con importante militancia teatrera feminista, como así también en múltiples iniciativas generadas por la Representación Provincial del INT. Su representante Jimena Sivila Soza, resistió a los envistes políticos que mencionamos, y trabajó incansablemente en consecuencia. Desarrolló planes de fortalecimiento regional, asumiendo una perspectiva de derechos humanos y de género como política central de fomento a la actividad teatral y de resistencia a la dominación conservadora y patriarcal.

Entre las acciones promovidas se organizaron por primera vez Plenarios Regionales de Teatro del NOA. El primero se desarrolló en el pueblo de Tilcara, en el "interior del interior" jujeño, en noviembre del año 2016. La segunda edición sucedió en San Miguel de Tucumán, en junio de 2018. Y el último ocurrió en formato virtual, en noviembre de 2020. Los encuentros propiciaron la problematización y reflexión sobre las diversidades del teatro de la región, impulsando el trabajo en red como estrategia de fortalecimiento, con prevalencia en la transversalización de debates de género en el teatro.

La representación del INT Jujuy organizó también un Ciclo de Teatro y Géneros, que finalizó con unas Jornadas Regionales de Teatro y Géneros en septiembre de 2019, un espacio sumamente movilizador y enriquecedor en el que se relataron experiencias artísticas, proyectos socioculturales, políticas públicas e independientes, militancias, casos de violencias institucionales o individuales, ocurridos en la región en estos años. También se presentaron obras de teatro y performance feministas y se pusieron en debate problemáticas regionales en la compleja relación entre ética, política y estética desde una óptica regional descolonizadora.

En este contexto de urgencia y necesidad de lucha, reflexión y acción por derechos de género en intersección con cuestiones de sexualidad, etnia, raza y clase, participantes a las Jornadas creamos un nuevo espacio: La Pluriteatral (Asamblea permanente plurinacional de trabajadorxs teatrerxs trans-feministas-disidentes del NOA), con el deseo de aportar mirada crítica y militancia al teatro de la región. Un año después en el contexto del tercer Plenario dicha organización confluiría en una agrupación independiente ampliada: el Observatorio de Género y Teatro NOA.

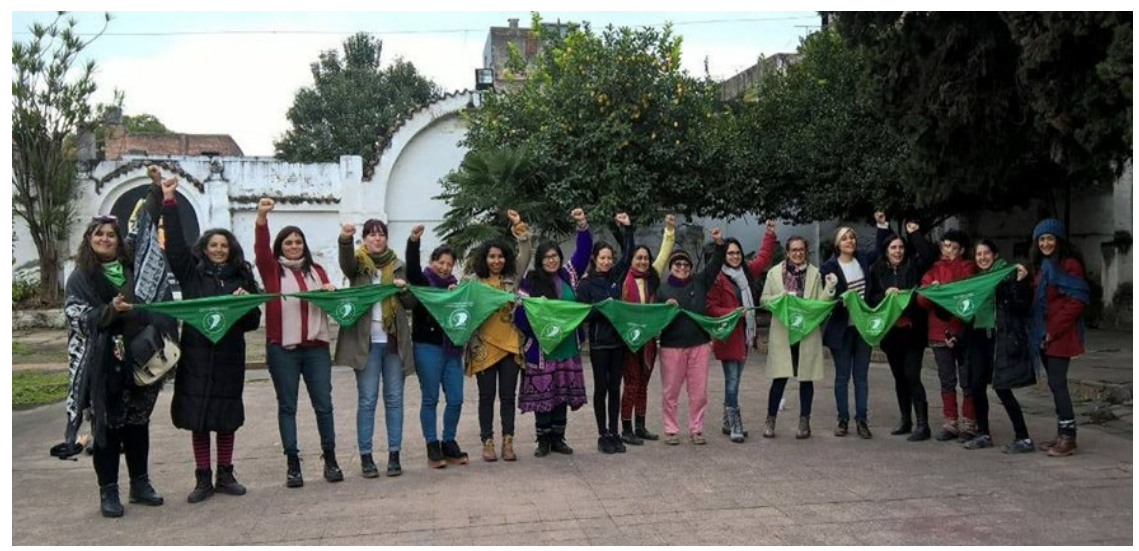




\section{Teatralidades de la manifestación versus espectacularización de la política gubernamental}

En otra dimensión de análisis encontramos en este período que el teatro ocurre particularmente en tensión entre dos fenómenos que se manifiestan en simultáneo, por un lado la multiplicación de teatralidades de la resistencia o de la manifestación (Diéguez, 2008) que no responden estrictamente al campo disciplinar del teatro ni tienen los mismos objetivos, pero que utilizan sus herramientas para proyectos de militancia sociopolítica; y por otro lado la proliferación de escenas de transteatralización (Dubatti, 2016) o espectacularización de la política gubernamental, en la que también se hacen de los recursos del teatro, pero para construir personajes o escenas presentadas como la realidad misma.

Llamamos transteatralización a la exacerbación y sofisticación del dominio de la teatralidad fenómeno extendido a todo el orden social- a través del control y empleo de estrategias teatrales, pero, en la mayoría de los casos, para que no se perciban como tales. Abonada por el auge de la mediaticidad y la digitalización (Dubatti, 2016: 10).

Las crisis de representación política o el vacío representacional que se extiende en estos años junto a los efectos de producción de "posverdad" en los que nos vimos insertxs nos obligó a repensar la representación teatral indefectiblemente, así como las teatralidades sociales que disputan el poder de la representación.

Las teatralidades de las manifestaciones callejeras de las mujeres, las disidencias $u$ otros grupos subalternos emergieron de manera contrastante a las transteatralizaciones de la política gubernamental, y se presentaron como acciones fundamentales que pusieron en juego no sólo una política de la mirada (Féral, 2005) -en la que se producen acciones disruptivas en el espacio intersubjetivo y social del espacio público para ser miradxs y observar la realidad al mismo tiempo-, sino también un ejercicio performativo del "derecho a la aparición" (Butler, 2017), mostrando y inundando las calles con presencias históricamente invisibilizadas, y proponiendo la búsqueda de nuevos significados mediante acciones públicas colectivas de gran potencialidad política. Desde una óptica sociopolítica planteada por los estudios teatrales, las teatralidades de la manifestación tienen como finalidad impugnar las representaciones oficiales establecidas, al detener temporalmente sus reglas e instituciones, a través de la irrupción en el orden cotidiano y la asunción de la autorepresentación habitualmente vedada.

Creemos que las teatralidades de la resistencia y de la manifestación se presentan como acontecimientos liminales entre el arte y la vida, más allá del teatro, y permiten renovar la representación como propuesta

${ }^{6}$ Pañuelazo por el aborto legal de teatreras participantes del $2^{\circ}$ Plenario Regional de Teatro del NOA, Teatro Paul Groussac, San Miguel de Tucumán, 3 de junio de 2018. 
colectiva de nuevos sentidos, tanto en la esfera política como en la esfera artística, siguiendo las propuestas teóricas de lleana Diéguez (2008). Muchxs teatrerxs de la región NOA nos volcamos a poner el cuerpo y llevar acciones artísticas a la calle en lucha porque es allí donde encontramos nuevos significados y objetivos político-estéticos en estos cuatro años terribles de gobierno de derecha conservadora.

Pero un poco antes al período mencionado, en mayo de 2015 -y entendiendo que los reclamos feministas trascienden gobiernos con distinto tinte político-apareció asesinada la adolescente Chiara Páez, y los pedidos de justicia por este femicidio junto a índices alarmantes de violencia de género en Argentina, impulsó la primera movilización masiva en contra de los femicidios en distintas ciudades del país. Periodistas mujeres organizaron y convocaron al primer Ni Una Menos el 3 de junio de ese año. Más de ochenta ciudades argentinas, y varias de la región NOA, se sumaron a estas demandas dolorosas y urgentes en movilizaciones masivas. Las marchas y acciones por la legalización del aborto también fueron centrales desde el año 2018. La campaña por el aborto legal, seguro y gratuito promovió las primeras organizaciones de actrices en distintas provincias, impulsada por Actrices Argentinas, de conformación principalmente porteña. Dotándole de características propias territoriales, las teatreras de cada provincia del NOA nos organizamos para acompañar esta lucha desarrollando diversas acciones artísticas en el espacio público de la calle y en espacios virtuales. Algunas de estas organizaciones surgidas en ese momento continúan trabajando hasta el día de hoy, y fueron ampliando sus luchas en estos años a otras demandas y problemáticas de género.

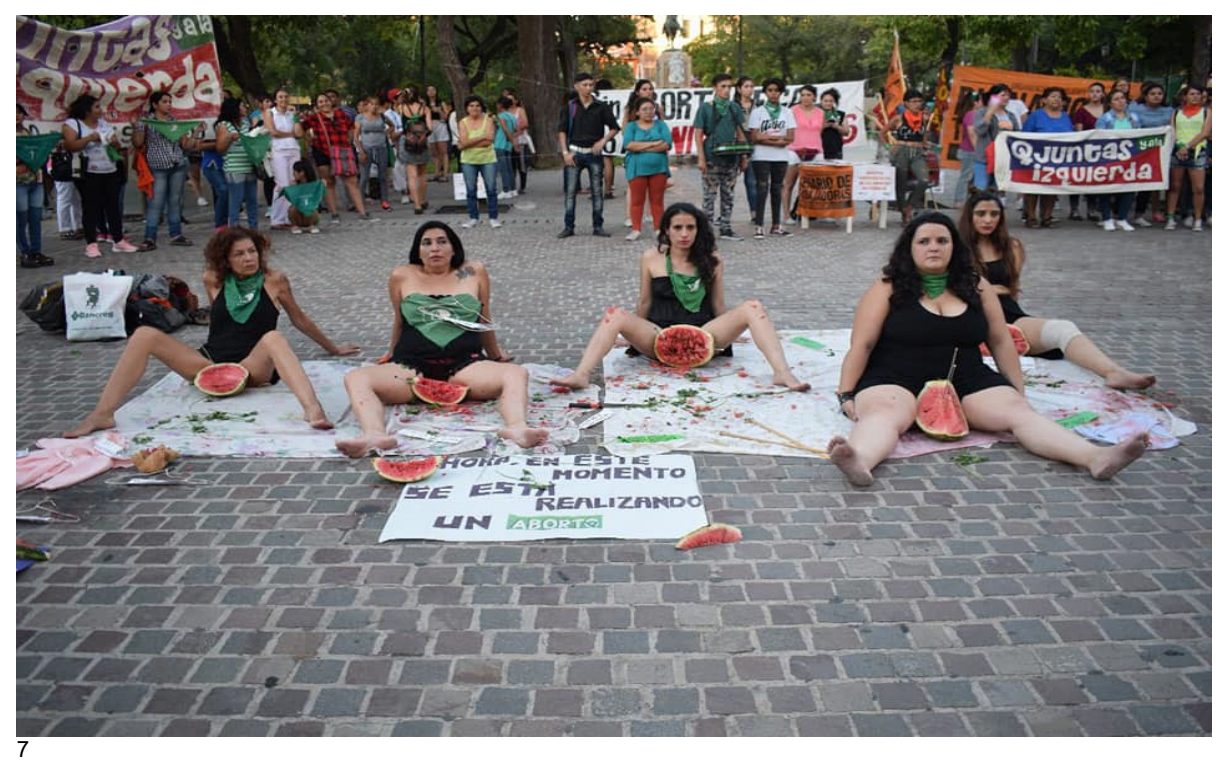

\footnotetext{
${ }^{7}$ Performance del Grupo Performático Mariposas, realizada el 19 de febrero de 2018, en la ciudad de Santiago del Estero, en el contexto de acciones colectivas por el aborto legal, seguro y gratuito de distintas organizaciones feministas. Fotografía: Yanina Sotelo.
} 
Las teatralidades de las manifestaciones deben leerse en esa frontera y mixtura entre la proposición de acciones cercanas al lenguaje performático o teatral y también en la proliferación de teatralidades sociales que despliegan acciones extracotidianas con lenguajes simbólicometafóricos. Por ejemplo, en Santiago del Estero el Grupo Performático Mariposas viene manifestándose hace varios años con intervenciones urbanas en diversas fechas emblemáticas vinculadas a los derechos humanos, los derechos de las mujeres y los colectivos LGTBQ+. Así también la colectiva que acompaña a mujeres a interrumpir el embarazo Socorro Rosa de Tucumán presentó distintas acciones artísticas en distintas movilizaciones. La performance de la virgen abortera en las puertas de la Catedral de San Miguel de Tucumán, en la marcha del 8 de marzo de 2017, es recordada por la ola de persecución y violencia contra las activistas que se suscitó en las redes sociales y desde instituciones conservadoras de la provincia. La colectiva Actrices Jujeñas, por su parte, viene desarrollando un trabajo muy activo, al proponer distintas manifestaciones de denuncia y visibilización de problemáticas de abusos, desigualdades y violencias en el campo teatral jujeño, y al utilizar también el lenguaje performático y visual, tanto en espacios públicos de la calle como en formatos virtuales.

Los feminismos cuestionan hace varias décadas la esencialidad del género, señalándolo como construcción cultural y social fruto de condiciones políticas e históricas, y denuncian la desigualdad y opresión largamente naturalizadas de un género sobre otros disidentes y subalternos en el sistema patriarcal y capitalista. Los feminismos se presentan como proposiciones teóricas, pero también y sobre todo como militancias por los derechos de las mujeres y las disidencias históricamente sometidas, en intersección con otras opresiones.

Las luchas feministas activistas y artivistas resisten a las normas establecidas, y de la exclusión en el espacio privado históricamente designado a las mujeres nos volcamos a los espacios públicos, poniendo el cuerpo y el deseo de cambiarlo todo como ejes centrales. "Estas manifestaciones tienen en la precariedad su impulso fundamental" (2017: 17) señala Judith Butler. Los cuerpos tanto tiempo invisibilizados, estigmatizados y violentados, se reúnen en la esfera pública donde hacer visibles diversas demandas, incluso a riesgo de ser reprimidos por las fuerzas del Estado o violentados por la sociedad civil.

La "potencia feminista" desplegada en estas experiencias refieren, como define Verónica Gago, "a una teoría alternativa del poder" (2019: 9). El ejercicio performativo del "derecho a la aparición" se muestra como una "reivindicación corporeizada de una vida más vivible" (Butler, 2017: 31) más justa e igualitaria. Asimismo, el ocultamiento al que había sido confinado durante tanto tiempo el tema del aborto en Argentina, por ejemplo, se vio obligado al debate público en la calle, en los medios de comunicación y en el Congreso Nacional gracias a la presión ejercida por las manifestaciones masivas de mujeres y cuerpos gestantes en la plaza pública. Los múltiples y masivos "pañuelazos verdes", organizados por la Campaña Nacional Por el Derecho al Aborto Legal, Seguro y Gratuito, realizados a lo largo y ancho 
del país, en los que millones alzamos nuestros pañuelos verdes con la consigna de "Educación sexual para decidir, anticonceptivos para no abortar y aborto legal para no morir" y cantamos colectivamente nuestros reclamos, así lo demostraron.

Observamos en estas experiencias como el cuerpo individual se vuelve colectivo en el encuentro social en lucha y disputa el poder político y el poder de la representación. Toma el espacio público, se reúne y expone una presencia alternativa que discute con las representaciones asignadas históricamente, desobedece a las representaciones estereotipadas adjudicadas a las corporalidades y muestra en contraste un cuerpo empoderado, emancipado y expresivo que batalla al cuerpo normalizado. Una "estética política-corpórea" lo llama Lola Proaño Gómez (2020), en cuyas características destaca la solidaridad y la afectividad, opuestas a los comportamientos propugnados por el neoliberalismo.

Así también, el concepto de teatralidad, propuesto por Josette Féral, nos permite hacer lecturas específicas sobre estas manifestaciones. La teatralidad es un proceso que pone en juego una política de la mirada, en donde un colectivo expone algo que perturba al mundo cotidiano establecido, o donde alguien posa la mirada sobre alguien o sobre un grupo que llama la atención, es decir, y como también sostiene Jorge Dubatti, se propone organizar "la mirada del otro y dejarse organizar la propia mirada por la acción del otro y establecer un juego en ese diálogo de miradas" (2016: 9). Los múltiples procesos de politicidad de las teatralidades de la resistencia y la manifestación es una puesta en cuerpo y acción disruptivas que crea un espacio otro, distinto al cotidiano, más igualitario, inclusivo, rebelde y crítico, en diálogo entre grupos sociales e instituciones estatales.

En el contexto de la región NOA, caracterizada por gobiernos y estructuras sociales ultracatólicas y conservadoras, que se oponen sistemáticamente a otorgar derechos largamente requeridos, o a hacer cumplir o adherir a algunos ya conseguidos a nivel nacional como la Ley de Educación Sexual Integral, o la Ley Micaela ${ }^{8}$, por nombrar algunas leyes, torna a las movilizaciones feministas especialmente significativas y relevantes en estos territorios.

En síntesis, y como venimos exponiendo hasta aquí, las teatralidades de la resistencia y la manifestación feministas se presentan como acontecimientos liminales entre el arte y el activismo y entre el arte y la vida, se desarrollan en espacios y escenarios sociales y no artísticos, hacen uso de objetos específicos (como los pañuelos verdes), gestos corporales, acciones, palabras, danzas, cantos y rítmicas singulares que batallan contra la normalización y la dominación de género en intersección con otras opresiones. Estas prácticas permiten reformular la representación como producción colectiva de nuevos sentidos en la esfera pública y recrear corporalidades políticas que desarrollan acciones con contenidos simbólicos y rituales alternativos, irrumpiendo y desbarajustando el orden espacial y temporal establecido.

8 La Ley Micaela fue promulgada el 10 de enero de 2019. Dispone la capacitación obligatoria en género y violencia de género para todas las personas que se desempeñan en la función pública, en los poderes Ejecutivo, Legislativo y Judicial de la Nación. 


\section{El teatro como práctica política feminista}

Encontramos también en este periodo algunas propuestas significativas de obras de teatro en la región que abordan las problemáticas y demandas expuestas por los feminismos y que fueron indefectiblemente afectadas por las dimensiones o los temas tratados en los puntos anteriores de este escrito. Estos proyectos teatrales se ocupan no sólo de pensar las temáticas feministas sino principalmente de repensar sus propuestas formales, entendiendo que es allí donde se juega la politicidad del teatro. Es decir, ponen en crisis las estructuras de representación sostenedoras y reproductoras de las estructuras sociales desiguales y coercitivas, asumiendo para ello las particularidades estético-culturales de nuestros territorios con perspectiva descolonizadora de los saberes y las prácticas teatrales.

Por ejemplo, el grupo La Otra Vuelta Artes Escénicas de Salta en el año 2016 presentó Aklla Sumaq: la elegida por su belleza, dirigida por Diego López. En una provincia con los mayores índices de femicidios del país, la obra se propuso tratar la difícil problemática. Recuperó en su título el nombre de un rito incaico en donde las mujeres o niñas eran reclutadas para servir al imperio, planteándose con ello reaparecer como metáfora de rituales de la tradición salteña que perpetúan estereotipos de género y opresiones o actos de violencia extrema como los femicidios llevados a cabo contra las mujeres por su condición de género. Destacamos en esta obra una propuesta teatral que se propone visibilizar y reflexionar sobre los comportamientos sociales como constructos estereotípicos y la violencia que emana de ellos en un contexto situado.

Otra obra teatral del mismo año se ocupaba también de la violencia de género, en este caso dentro de las relaciones de pareja, La celebración de la provincia de Tucumán, creación colectiva dirigida por Tatiana Luján Valdéz. En los límites de la ficción y la realidad, el público era invitado a participar a una fiesta de cumpleaños con características territoriales y en la que se sucedía una escena muy violenta de género. En esa misma invitación el espectador era interpelado a reaccionar frente aquella situación. Las intervenciones del público resultaron de las más variadas: desde asombro e inacción, hasta enojo y demanda furiosa a los personajes. 


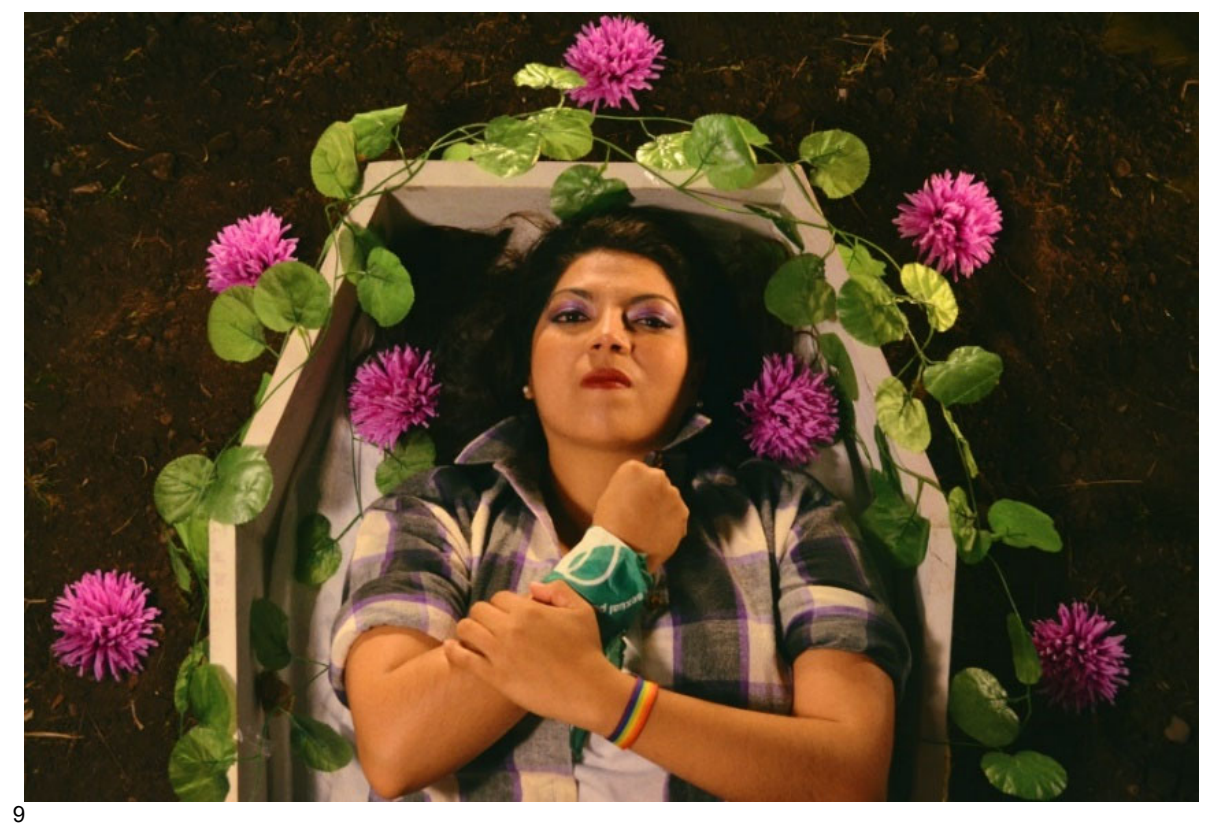

La obra teatral Réquiem Inducido, estrenada en el año 2017, del grupo jujeño Circo Cromático, dirigida por Martín Mendoza, abordó los debates sobre la legalización del aborto a través de un muestrario paródico de personajes de nuestro territorio norteño: desde un cura, pasando por una enfermera opositora al aborto, hasta una lesbiana abortera. La obra fue censurada por el estatal Teatro Mitre de San Salvador de Jujuy, y tras movilizaciones y reclamos públicos se pudo finalmente representar allí. El grupo en el año 2018 estrenó Nosotrxs, comprometiéndose con otro problema al que nos enfrentamos en nuestras provincias, la resistencia a la implementación de la Ley de Educación Sexual Integral (ESI). El grupo ideó una alternativa teatro-didáctica para llevar a cabo en las escuelas, aprovechando espacios áulicos reales representaban allí una clase de ESI abierta a la participación de Ixs alumnxs/espectadores.

Uno de los grupos emblemáticos de la región, con diversos trabajos desde la perspectiva de género, es Manojo de Calles de la provincia de Tucumán, dirigido por Verónica Pérez Luna. Durante el año 2017 estrenaron la obra Pedro y Las Pelonas o exvotos al teatro. La obra se preguntaba en clave esperpéntica y "monstruosa" sobre los límites y las posibilidades del cuerpo, sobre el "cuerpo del teatro" y sobre el cuerpo de las actrices que portan sobre sí la historia de más de veinte años de trabajo teatral. También en el límite entre ficción y realidad, la directora daba órdenes desde la cabina de luces a las actrices en escena, e interactuaba desde las sombras con el público si se animaba a intervenir. Así, la obra interrogaba también a la relación entre directora y actrices, y obra y espectadores, una problemática central en la creación y producción teatral desde la perspectiva feminista. Creemos que es necesario y urgente repensar la división del trabajo y el orden jerárquico de roles heredados de

\footnotetext{
${ }^{9}$ La actriz Pantu Vera en la obra Réquiem Inducido, fotografía de Bárbara Rodríguez Berman.
} 
la modernidad europea en que el autor/a y el director/a, ya sean varones o mujeres, se presentan todavía como figuras principales en la construcción de sentido. Incluso en los intentos y avances democratizadores de creaciones colectivas en el teatro parece no haberse avanzado en profundidad en las desigualdades estructurales.

Estas breves reseñas teatrales muestran un panorama de teatro feminista descolonial en la región NOA, cuyas propuestas sostienen concepciones de cuerpo, espacio, representación y encuentro entre participantes, que recuperan características y condiciones territoriales particulares, asumen el origen colonial de la opresión y las desigualdades sobre las mujeres y los cuerpos subalternos, y se plantean no solo temáticas urgentes de las agendas feministas sino también conceptos estéticos como los de "monstruosidad" latinoamericano propuesto por Rodolfo Kusch.

Como señalamos hasta aquí, ética, estética y política, así como práctica artística, gestión institucional y militancia, se entrelazan y dialogan fructíferamente en la región NOA en este período. Por un lado, el estudio y la puesta en diálogo de esta diversidad de experiencias puede ser fuente de conocimiento a través del cual comprender teatralidades y prácticas teatrales singulares y complejas que trascienden los límites del teatro, pero que lo ponen en discusión y lo retroalimentan indefectiblemente. Y, por otro lado, nos proponemos con estas reflexiones sobre prácticas feministas en teatro contribuir a pensar e intervenir en la realidad desigual y violenta en la que vivimos.

\section{Referencias bibliográficas}

BUTLER, Judith. Cuerpos aliados y lucha política. Hacia una teoría performativa de la asamblea. Buenos Aires: Paidós, 2017.

DIÉGUEZ CABALLERO, lleana. Escenarios liminales. Buenos Aires: Atuel.

DIÉGUEZ CABALLERO, Ileana. "El malestar de las teatralidades", en Revista KARPA 1.1, 2007.

http://www.calstatela.edu/misc/karpa/Karpa1/Site

Folder/ileanadiegueza.html

DUBATTI, Jorge. Teatro- matriz, Teatro liminal. Estudios de Filosofía del Teatro y Poética Comparada. Buenos Aires: Atuel, 2016.

FÉRAL, Josette. "La teatralidad: en búsqueda de la especificidad del lenguaje teatral", en Teatro, teoría y práctica: más allá de las fronteras. Buenos Aires: Galerna. Págs. 87-107, 2005.

GAGO, Verónica. La potencia feminista: o el deseo de cambiarlo todo. Ciudad Autónoma de Buenos Aires: Tinta Limón, 2019.

KUSCH, Rodolfo. América profunda. Buenos Aires: Biblos, 1999.

PROAÑO GÓMEZ, Lola. "Estallido social/estallido feminista: Chile y argentina 2015-2019", en Revista Artescena Nº9. Págs. 1-21, 2020.

QUIJANO, Aníbal. "Colonialidad y modernidad/racionalidad", en Perú Indígena vol. 13 n²9. Lima, 1992.

SARMIENTO, Domingo Faustino. Facundo, o Civilización y barbarie. Buenos Aires: Biblioteca del Congreso de la Nación Argentina, 2018. 
Ambigua, Revista de Investigaciones sobre Género y Estudios Culturales, n. ${ }^{\circ} 8,2021$, pp. 35-47. ISSN: 2386-8708

SVAMPA, Maristella. El dilema argentino: civilización o barbarie. Buenos Aires: Taurus, 2006. 